\title{
On the completeness of metric spaces with a $w$-distance
}

\author{
Aleksandar Kostic ${ }^{1}$ \\ ${ }^{1}$ Faculty of Sciences and Mathematics, University of Nis, Serbia
}

October 8, 2020

\begin{abstract}
Abstract. A $w$-distance on a metric space $(X, d)$ is a function $p: X \times X \rightarrow[0, \infty)$ which is lower semicontinuous with respect to the second varibale, satisfies the triangle inequality and for all $\varepsilon>0$ there exists a $\delta>0$ such that $p(z, x) \leq \delta$ and $p(z, y) \leq \delta$ imply $d(x, y) \leq \varepsilon$ for all $x, y, z \in X$. In this short note we prove that a metric space with a $w$-distance $p$ is complete if and only if every sequence $\left\{x_{i}\right\}$ such that $\sum_{i=1}^{\infty} p\left(x_{i}, x_{i+1}\right)<\infty$ converges.
\end{abstract}

The notion of $w$-distance on a metric space was introduced and studied bu Kada et al. in [2].

Definition 1. Let $(X, d)$ be a metric space. A $w$-distance on $X$ is a function $p: X \times X \rightarrow[0, \infty)$ satisfying the following conditions:

(P1) $p(x, y) \leq p(x, z)+p(z, y)$;

(P2) $p(x, \cdot): X \rightarrow[0, \infty)$ is a lower semicontinuous function for all $x \in X$;

(P3) for all $\varepsilon>0$ there exists a $\delta>0$ such that $p(z, x) \leq \delta$ and $p(z, y) \leq \delta$ imply $d(x, y) \leq \varepsilon$;

for all $x, y, z \in X$.

We recall that a real-valued function $f$ defined on a metric space $(X, d)$ is lower semicontinuous at a point $x \in$ $X$ if for any sequence $\left\{x_{n}\right\} \subseteq X$ converging to $x$ we have that either $\liminf _{x_{n} \rightarrow x} f\left(x_{n}\right)=+\infty$ or $f(x) \leq$ $\liminf _{x_{n} \rightarrow x} f\left(x_{n}\right)$.

The following lemma shall be used to prove the main result.

Lemma 1. [4] Let $(X, d)$ be a metric space with a $w$-distance $p$. If $\left\{x_{n}\right\}$ is a sequence in $X$ such that

$$
\lim _{n \rightarrow \infty} \sup _{m>n} p\left(x_{n}, x_{m}\right)=0
$$

then $\left\{x_{n}\right\}$ is Cauchy.

We prove the following statement, which is the main result of this note.

Theorem 1. A metric space $(X, d)$ with a $w$-distance $p$ is complete if and only if :

(1) every sequence $\left\{x_{i}\right\} \subseteq X$ such that

$$
\sum_{i=1}^{\infty} p\left(x_{i}, x_{i+1}\right)<\infty
$$

converges to some $x \in X$. 
Proof. $\left(\Rightarrow\right.$ :) Let $(X, d)$ be complete, and let $\left\{x_{i}\right\} \subseteq X$ be a sequence such that $\sum_{i=1}^{\infty} p\left(x_{i}, x_{i+1}\right)<\infty$. Then for all $\varepsilon>0$ there exists $N_{\varepsilon} \in \mathbb{N}$ such that $\sum_{i=n}^{\infty} p\left(x_{i}, x_{i+1}\right)<\varepsilon$ for all $n \geq N_{\varepsilon}$. Hence, for all $m, n \in \mathbb{N}$ such that $m>n \geq N_{\varepsilon}$ we have

$$
p\left(x_{n}, x_{m}\right) \leq \sum_{i=n}^{m-1} p\left(x_{i}, x_{i+1}\right) \leq \sum_{i=n}^{\infty} p\left(x_{i}, x_{i+1}\right)<\varepsilon
$$

which implies that $\lim _{n \rightarrow \infty} \sup _{m>n} p\left(x_{n}, x_{m}\right)=0$, so by Lemma $1,\left\{x_{i}\right\}$ is Cauchy. Since $X$ is complete, $\left\{x_{i}\right\}$ converges to some $x \in X$.

$(\Leftarrow:)$ Now suppose that $(1)$ holds, but $X$ is not complete, so there exists a Cauchy sequence $\left\{x_{i}\right\} \subseteq X$ which is not convergent. Let $F=\left\{x_{i}: i \in \mathbb{N}\right\}$, and let $p: X \times X \rightarrow[0, \infty)$ be defined as

$$
p(x, y)=\left\{\begin{array}{l}
d(x, y), \text { if } x, y \in F, \\
2 \operatorname{diam} F, \text { otherwise. }
\end{array}\right.
$$

Since $\left\{x_{i}\right\}$ is Cauchy sequence which is not convergent, the set $F$ is closed and bounded, so $p$ is a $w$ distance on $X$ (see [2, Example 7]). Let $i_{j}$ be the least natural number such that $p\left(x_{n}, x_{m}\right)=d\left(x_{n}, x_{m}\right) \leq \frac{1}{2^{j}}$ for all $m, n \in$ such that $m>n \geq i_{j}$. Then we have

$$
\sum_{j=1}^{\infty} p\left(x_{i_{j}}, x_{i_{j+1}}\right) \leq \sum_{j=1}^{\infty} \frac{1}{2^{j}}<\infty
$$

which by (1) means that $\left\{x_{i}\right\}$ has a convergent subsequence $\left\{x_{i_{j}}\right\}$ which is impossible (since its limit would be the limit of the whole sequence).

Remark. In [5] the authors characterized completeness of metric spaces with a $w$-distance via generalized Banach's contraction, i.e. the weak contraction. In [3] the author of the present paper introduced the functions $\delta_{p}$ and $\alpha_{p}$ (p-diameter and Kuratowski $p$-measure of noncompactness) on such spaces and studied the metric completenes via those functions. Hence, we can now formulate our second main result, which represents an analogue of [1, Theorem I.5.1] for metric spaces with a $w$-distance, and summarizes all known characterizations of completeness for such spaces. For the definition of weak contraction we refer the reader to [5], and for the definitions of $\delta_{p}, \alpha_{p}$ to [3].

Theorem 2. Let $(X, d)$ be a metric space with a $w$-distance $p$. The following conditions are equivalent.

(i) $X$ is complete;

(ii) Every weak contraction on $X$ has a uniqe fixed point;

(iii) Every sequence $F_{n}$ of nonempty closed subsets in $X$ such that $F_{n+1} \subseteq F_{n}$ for all $n \in \mathbb{N}$ and $\lim _{n \rightarrow \infty} \delta_{p}\left(F_{n}\right)=0$ has a singleton intersection;

(iv) Every sequence $F_{n}$ of nonempty closed subsets in $X$ such that $F_{n+1} \subseteq F_{n}$ for all $n \in \mathbb{N}$ and $\lim _{n \rightarrow \infty} \alpha_{p}\left(F_{n}\right)=0$ has a nonempty compact intersection;

(v) Every sequence $\left\{x_{i}\right\}$ such that $\sum_{i=1}^{\infty} p\left(x_{i}, x_{i+1}\right)<\infty$ converges.

Proof. (i) $\Leftrightarrow$ (ii) is proven in [5, Theorem 4], (i) $\Leftrightarrow$ (iii) $\Leftrightarrow$ (iv) is proven in [3, Theorem 3.1] and (i) $\Leftrightarrow$ (v) is Theorem 1 of the present paper.

\section{References}

[1] I. Arandjelovic: Stavovi o presecanju i njihove primene u nelinearnoj analizi (in Serbian), PhD thesis, Faculty of Mathematics, University of Belgrade (1999) 
[2] O. Kada, T. Suzuki, W. Takahashi: Nonconvex minimization theorems and fixed point theorems in complete metric spaces. Math. Japon. 1996, 44: 381-591.

[3] Aleksandar Kostić : Measures of noncompactness on w-distance spaces, author's preprint, DOI: $10.13140 /$ RG.2.2.14302.46402

[4] T. Suzuki: Several fixed point theorems in complete metric spaces. Yokohama Math. $J$ 1997, 44: 61-72.

[5] T. Suzuki, W. Takahashi: Fixed point theorems and characterizationsof metric completeness, Topological Methods in Nonlinear Analysis, 8(1996), 371-382 